\title{
Arbor
}

\section{Los contenidos de la ciencia y los progresos de la técnica en la Edad Media}

\section{Yolanda Guerrero Navarrete}

Arbor CLIX, 625 (Enero 1998), 69-107 pp.

El presente artículo pretende, por encima de todo, introducir al lector en el desconocido mundo del conocimiento científico y de los progresos que en materia de tecnología conoció la Edad Media europea. En este sentido, con el fin de dimensionar en su estricto nivel y en el seno del sistema social al que pertenece la ciencia y técnica medievales, considero imprescindible iniciar el trabajo presentando los límites culturales, sociales y filosóficos en los que hubo de desenvolverse dicho conocimiento, ese "magma cultural»-como lo he designado-, que impone determinadas preguntas al medio, y no otras, que restringe y proporciona respuestas en un sentido $y$ no en otro y que, en definitiva, está condicionando el interés, la curiosidad y la capacidad de percepción del hombre medieval con respecto a su entorno natural. Sólo sobre esta base, podré más adelante, en un segundo momento, internarme en la descripción de los progresos cientificos y técnicos que nosotros, europeos del siglo $X X$, heredamos de nuestros denostados $y$ bárbaros antepasados de la Edad Media.

Resumir en las pocas páginas de que dispongo toda la historia de la ciencia y de la técnica en la Edad Media es una tarea realmente difícil. Por ello espero que nadie pretenda obtener de la lectura de 


\section{Yolanda Guerrero Navarrete}

este artículo otra cosa sino una puesta a punto introductoria ${ }^{1}$-estimulante, espero, de nuevos campos de interés sobre el tema- en torno a la ciencia y técnica medievales. El espacio de que dispongo me impone, de entrada, una primera limitación: la espacial. En justicia, una historia de la ciencia y de la técnica en la Edad Media debería abarcar, como mínimo, el ámbito europeo occidental, la cultura islámica y hebrea y ciertas culturas del oriente lejano: India y China fundamentalmente ${ }^{2}$. Voy a centrarme sólo en el primero por las siguientes razones. Primero, porque somos europeos y el objetivo primordial de la historia es comprender nuestro presente a través de nuestro pasado. Segundo, porque en definitiva, la ciencia y el conocimiento científico es una invención exclusivamente europea. Desde aproximadamente el siglo XIII comenzaron a afluir al occidente europeo los logros alcanzados en materia científica por los árabes. La importancia de éstos en la historia de la ciencia es enorme, pero su labor fue, en última instancia, una labor de conservación y transmisión. A su través Europa, la Europa medieval, conoció la herencia greco-latina, que sólo el Islam había sabido conservar durante la Alta Edad Media, y gran parte de la ciencia hindú y persa, asimilada por el Islam tras sus conquistas. Frente a esta labor de transmisión, las aportaciones originales árabes carecen de importancia. China, a su vez, inventó la imprenta, la pólvora y la brújula dos siglos antes de que su uso se difundiera en Europa. Pero el inmovilismo que siempre caracterizó a la sociedad china hizo que dichos progresos sólo se perfeccionaran, utilizaran y difundieran en Occidente. China nunca utilizó ninguno de sus inventos. Así, la ciencia de la que somos herederos nace exclusivamente en Europa. Sólo aquí se dieron las condiciones que permitieron a la sociedad occidental no sólo ser permeable a las herencias, sino construir a partir de ellas. Empezando por los escolásticos del medievo, todos los científicos e intelectuales occidentales han sometido estas herencias, prácticamente desde su misma recepción, a una profunda y enriquecedora crítica hasta construir un sistema de conocimiento único que constituye una de las grandes aportaciones del occidente europeo a la humanidad.

Ahora bien, si el conocimiento científico contemporáneo es, por definición europeo, no es menos cierto que sus orígenes son incuestionablemente medievales. Constituye ya un tópico afirmar que la Edad Media significa un período de oscurantismo intermedio entre la brillantez de la civilización grecolatina y la recuperación cultural del humanismo renacentista. Mi intención es, entre otras cosas, reivindicar para la etapa medieval el lugar que le corresponde y estoy segura de poder demostrar que, si bien es verdad que toda la ciencia medieval 
y, por consiguiente también la moderna, se basa en la recepción de la herencia grecolatina, no es menos cierto que fueron los escolásticos medievales quienes iniciaron esa crítica profunda y constructiva que culminará en la llamada revolución científica del XVIII. Además, lejos ya de viejos espejismos estéticos, podemos hoy afirmar que si el humanismo fue una etapa brillante en cuanto a producción artísitica y literaria se refiere, en términos de ciencia de la naturaleza significó un considerable retroceso.

En gran medida, esa persistente imagen de época oscura viene avalada por una sólida ignorancia de lo que podríamos denominar magma cultural del medievo, ignorancia a la que confieso no somos ajenos los propios medievalistas y que, sin duda, es preciso ya desterrar ${ }^{3}$. Hacer historia de la ciencia no es ujuzgar" desde la soberbia que nos proporciona la superioridad de nuestro tiempo la mayor o menor ignorancia de las etapas pasadas, sino tratar de comprender las metas, concepciones y soluciones del pasado TAL COMO SE DIERON $O S E$ PODIAN DAR EN EL PASADO. La ciencia constituye una expresión más de una sociedad dada. Eso significa que, en primer lugar, a su través podemos conocer mejor dicha sociedad, pero, sobre todo, que sus logros en el campo de la ciencia están condicionados a los límites que dicha sociedad impone al conocimiento. Eso que podría designar como "magma cultural» es lo que está determinando qué tipo de problemas despiertan la curiosidad de los hombres sobre el mundo natural en un momento dado; qué respuestas pueden dar; $y$, en definitiva, qué rasgos característicos de un sistema social limitan los logros científicos en términos de filosofía de la naturaleza, método científico, y técnicas de observación, experimental y matemática, asi como qué cambios provocaron el paso de un punto de vista a otro. Por ello, antes de pasar a comentar los progresos de la ciencia y de la técnica medievales, merece la pena detenerse un poco en comentar los límites, etapas y evolución del conocimiento científico en el medievo.

\section{El conocimiento científico en la Edad Media: límites, condicionantes y etapas}

Dos son los aspectos que conforman el magma cultural de cualquier sociedad y que establecen el perímetro por el que le es permitido expandirse al conocimiento científico. Ambos son teóricos e interdependientes y, por ello, difíciles de separar. Los trataré simultáneamente. Me refiero, por un lado, a LAS CATEGORÍAS CULTURALES (espa- 


\section{Yolanda Guerrero Navarrete}

cio/temporales), que determinan la visión del mundo de cada sociedad y que suscitan por tanto las preguntas a las que dar respuesta $y$, por otro, a LAS CATEGORÍAS FILOSÓFICAS, que condicionan dichas respuestas a un sistema de pensamiento concreto ${ }^{4}$.

Si observamos una pintura medieval percibimos inmediatamente que el munco recreado por el artista nos resulta a nosotros, hombres del siglo XX, como mínimo insólito y peculiar. Para empezar los temas: todos ellos relativos a Dios o a lo sagrado. No existe ningún tema profano en el arte medieval. En segundo lugar, los pintores medievales parecen ignorar que el mundo es tridimensional, que tiene profundidad. Parecen también ignorar, en tercer lugar, cómo transcurre el tiempo pues muchas veces se plasman evidentes anacronismos, ropas o costumbres no pertenecientes a la época, e incluso se reproducen muchas veces cierlas acciones como simultáneas. Si a consecuencia de esto calificamos a los medievales de burdos ignorantes o fanáticos religiosos estaremos empezando mal. Es muy fácil hablar de "primitivismo", de «ineptitud". Ello sólo pondría de manifiesto la incomprensión del mundo interno del pintor o poeta medievales y el deseo de juzgar el arte de otra época basándonos en criterios de hoy. Lo inteligente es pensar que su arte responde a su concepto del mundo y, por tanto, a su percepción de la realidad.

Primero, la idea de Dios. Merece la pena dedicarle un brevísimo tiempo. Para el hombre medieval, la existencia de Dios es un axioma. Dios es la verdad suprema para los hombres de la Edad Media y en torno a ella se organizan todas sus representaciones e ideas. En la Edad Media, el género literario más difundido y popular es la vida de los santos; la muestra más típica de arquitectura la constituye la catedral; en la pintura predomina el icono y en la escultura los personajes de las Sagradas Escrituras. Ello es así, no sólo porque dicha idea de Dios impregne todas las conciencias, sino porque además, los intelectuales de la edad Media eran mayoritariamente clérigos. Durante muchos siglos, la Iglesia mantuvo el absoluto monopolio de la cultura. En lo que al presente tema afecta, ello impone dos límites al conocimiento científico: en primer lugar, debe ser por definición integral. Cuando los pensadores medievales estudiaban lo hacían siempre con la intención de comprender y magnificar a Dios. El hombre y el mundo contenían en sí mismos toda la lógica y magnificencia de la creación.Todo, hasta la más ínfima partícula, participa de la misma inspiración: el microcosmos era en cierto modo una copia del macrocosmos. En segundo lugar, la sacralización del conocimiento hacía obligado que cuando los científicos medievales razonaban sobre cualquier cosa: la popiedad, la 
riqueza, el cosmos, el precio o el trabajo estuvieran razonando necesariamente sobre categorías éticas. Así, los símbolos matemáticos eran a la vez símbolos teológicos y el número era, sobre todo, un elemento esencial del pensamiento estético y un símbolo sagrado.

Si nos resulta primitiva esta idea teológica del conocimiento, no menos extraño es a nosotros el sentido del tiempo y la noción del espacio que poseían y practicaban los hombres de la Edad Media. La sociedad postindustrial posee una actitud consciente hacia el tiempo. Es capaz de prever el futuro, planificar su actividad y determinar a largo plazo el desarrollo de la ciencia, de la técnica, de la producción y de la sociedad. Tomada la sociedad en su conjunto, nunca se ha valorado tanto el tiempo ni ha ocupado un lugar tan importante en la conciencia del hombre como en la época actual. De la misma manera ha cambiado el espacio: ha resultado que éste podía contraerse. Los nuevos sistemas de transporte y de comunicaciones han hecho posible recorrer por unidad de tiempo distancias incomparablemente superiores a las de hace unas cuantas decenas de años, sin hablar ya de un pasado muy lejano. El mundo se ha hecho más pequeño. La velocidad, categoría que conjuga las nociones de espacio y tiempo, ha adquirido inmensa importancia en la actividad humana. Ha cambiado de manera radical, en su conjunto, el ritmo de la vida. Aunque nosotros lo veamos como algo natural, la humanidad no ha conocido nada semejante en toda su historia.

El paisaje de Europa a comienzos de la Edad Media era muy diferente del actual. La mayor parte del territorio estaba cubierto de bosque. Una gran parte de las tierras sin bosque eran pantanosas o cubiertas de barro. Las aldeas se encontraban frecuentemente en medio de inmensas extensiones de bosque que atraían por los recursos que ofrecían y que atemorizaban por los peligros que en ellos acechaban: animales salvajes, salteadores y otros individuos fuera de la ley, criaturas fantasmales y misteriosas y hechiceros con los que la imaginación poblaba de buena gana el mundo que rodeaba a los poblados. Las relaciones entre las aldeas eran limitadas y se reducían a contactos irregulares y superficiales dado que las vias de comunicación eran prácticamente inexistentes o se encontraban en un estado muy insatisfactorio. Viajar en la edad Media era una empresa peligrosa y de mucha duración. En 24 horas se podían recorrer como máximo algunas decenas de $\mathrm{Km}$. La noticia de la muerte de Federico Barbarroja en Asia Menor tardó cuatro meses en llegar a Alemania; los ingleses se enteraron al cabo de cuatro semanas que su rey Ricardo Corazón de León había sido hecho prisionero en Austria. El trayecto de Roma a Canterbury 


\section{Yolanda Guerrero Navarrete}

podía durar ordinariamente hasta siete semanas aunque las noticias urgentes podían ser transmitidas en cuatro semanas.

Asi, la visión predominante del mundo, la que dominaba la conciencia y la conducta sociales era la del agricultor. Vinculado a la tierra por la economía,absorto en los trabajos agrícolas, dominado por la naturaleza e incapaz de enfrentarse con éxito a ésta, el hombre concebía la naturaleza como parte integrante de sí mismo. El hombre vivía el espacio de forma subjetiva, se sentía incapaz de diferenciarse netamente de su entorno natural. El arte, la literatura y el folclore medieval poseen muchos restos. La más frecuente es la imagen del "cuerpo grotesco" (fiestas populares y carnavales del renacimiento), en donde el hombre se presenta como no disociado de la naturaleza: los hombres-animal o los hombres-planta del Bosco o Bruegel. Si el hombre es representado con formas naturales, no es menos frecuente la humanización de la naturaleza. Otra prueba: las medidas. La extensión y la superficie del suelo no se establecían con la ayuda de medidas y patrones absolutos: el codo, el palmo y el dedo eran las medidas más naturales y difundidas. Para establecer las medidas de tierra cultivada se utilizaban como base el tiempo de trabajo del hombre, la renta que podía obtenerse, el número de arados necesarios para cultivarla o la cantidad de simiente necesaria para sembrarla. Toda medida agraria en la Edad Media es concreta y local y está vinculada a una determinada propiedad y a $\mathrm{s}\lrcorner$ cultivo. Según el derecho islandés, una mujer podía apropiarse de toda la tierra que fuera capaz de recorrer a pie en un día llevando una vaca por el ronzal. La aproximación, la imprecisión son rasgos que caracterizan, por tanto, la noción de espacio en la Edad Media y su cuantificación.

Si la noción popular del espacio responde al mundo agrario, la cuestión se complica si nos atenemos al concepto y representaciones cultas del mismo. Por acción de la filosofia cristiana altomedieval, el neoplatonismo agustiniano, la noción de cosmos perdió la cualidad de armonía que la había caracterizado en la antigüedad. Si en el mundo antiguo el mundo era un todo armonioso, para el hombre de la Edad Media se trataba, en cambio, de un mundo dualista: la civitas dei $y$ la civitas terrae. La noción de naturaleza empezó a aplicarse sobre todo al universo humano y ya no era portadora de un alto valor ético y estético. El mundo cristiano ya no era bello porque estaba manchado por el pecado y sometido a la necesaria purificación que culminará en el juicio de Dios. La verdad sólo existe en el alma del hombre y nunca en el mundo exterior. La obra más hermosa de Dios no es la creación, síno la redención. La rehabilitación de la naturaleza no co- 
mienza en realidad hasta el siglo XII. Al poseer mayor capacidad que en los períodos anteriores para influir en el mundo que le rodea, el hombre comienza a prestarle mayor interés. Pero esta rehabilitación no es completa. Este interés no viene provocado por la naturaleza como tal. No es independiente, sino que se trata de una creación de Dios y a éste glorifica. Los filósofos del s. XII hablan de la necesidad del estudio de la naturaleza porque al conocerla el hombre se descubre a sí mismo y a Dios.

Esta percepción medieval de la naturaleza se plasma, no sólo en el tratamiento ofrecido por el medievo a la ciencia natural, sino, sobre todo, se traduce perfectamente en la representación estética y real de dicha naturaleza. El paisaje, componente inseparable del sistema artístico de los tiempos modernos, no existía como tal ni en las bellas artes ni en la literatura medievales. La naturaleza no existía objetivamnete al margen del hombre, por eso no podía ser concebida como un objeto de observación. Todas las menciones que la literatura concede a los espacios naturales lo son de forma simbólica. En la novela caballeresca, el bosque es tan sólo el lugar de peregrinación del caballero, el jardín es sólo el lugar de sus aventuras amorosas, el campo el lugar del duelo, etc. En la pintura se rechaza conscientemente la perspectiva lineal. La lejanía se representa reduciendo el tamaño de los objetos o personas. Todo se representa en un mismo plano, las figuras, contorneadas de negro, no se mezclan con el fondo. En la misma imagen coinciden claramente diferentes partes del espacio. El observador no es en la pintura medieval el centro a partir del cual se contempla la realidad. De hecho, ésta no interesa. El mundo visible, en el más puro neoplatonismo altomedieval no cuenta. Lo único real es lo que se percibe con los ojos del espíritu: la civitas dei, el mundo superior. La pintura medieval negaba toda existencia autónoma al mundo visible, sometido siempre al mundo suprasensible, único dotado de verdadera realidad. Es más, ambos estaban perfectamente comunicados. No existía una frontera clara entre lo natural y lo sobrenatural: los muertos podían volver al mundo de los vivos, del mismo modo que algunos vivos podían penetrar en el mundo de los muertos. A partir del siglo XIII comenzó a modificarse la noción del espacio: el individuo comenzó a percibirse a sí mismo como centro alrededor del cual se organiza el resto del mundo. Esta visión realista y antropocéntrica hizo que los pintores redescubrieran la perspectiva lineal que supone la presencia de un observador exterior que contempla desde un punto inmóvil todas las partes del cuadro.

Algo similar ocurre con la representación del espacio real. En la Edad Media, el mundo no era concebido como variado ni heterogéneo: 
el hombre tendía a juzgarlo a partir de su pequeño y estrecho universo personal. Si tenemos en cuenta que para el hombre medieval el mundo terrestre y el mundo sobrenatural vivían permanentemente mezclados, entenderemos que las ideas geográficas del período tampoco los distinguiera. La descripción del círculo terrestre incluía fragmentos de información real junto con representaciones bíblicas sobre el paraíso concebido como centro del universo. Mientras que un grupo de escritores medievales se apoyaba en los antiguos (Beda el Venerable) y creían así en la esfericidad de la tierra, otros autores, preocupados por el hecho de que esta concepción contradijese a la Biblia, unas veces afirmaban que la tierra era un disco plano (Casiodoro, Isidoro de Sevilla), otros intentaban compaginar ambas ideas (San Basilio). La geografía alegórica e la Edad Media, mezclaba en un mismo plano espacial la historia sagrada y la terrestre. En los mapas del mundo estaban representados el paraíso de Adán y Eva, los personajes bíblicos, Troya, las conquistas de Alejandro Magno, las provincias romanas, los lugares santos, los estados cristianos y el fin del mundo.

Sólo con el desarrollo de la civilización urbana, que contaba con un espíritu nuevo, más racionalista, esta concepción de la naturaleza empezó a modificarse. La complicación creciente de la actividad práctica del hombre, su acción más enérgica y determinada sobre la naturaleza, plantearon a su conciencia nuevos problemas. Al aumentar la curiosidad del epíritu humano, la naturaleza comenzó a desacralizarse, a secularizarse. La aparición de la industria hizo que aumentara también la necesidad de medir de maner más precisa y estandarizada los cuerpos y la velocidad. En la civilización urbana, el hombre estaba menos sometido ya a los ritmos naturales y empezaba a distinguirse a sí mismo de la naturaleza, lo que significaba tratar a ésta como objeto. El horizonte del hombre se amplía. Con el anuncio de la modernidad, desde el siglo XIII empieza a formarse en Europa un nuevo modelo del mundo. El espacio homogéneo y organizado de una manera nueva ocupa en él un lugar preeminente. Algo similar ocurre con la noción de tiempo.

Es un hecho conocido por todos que al cristianismo se debe una noción filosófica del tiempo absolutamente nueva. Un concepto lineal del tiempo que se corresponde sin duda con el sentido del tiempo y de la duración que poseemos en la actualidad. En ese concepto lineal, el pasado y el futuro tienen mucha más importancia que el efímero pasado. Sin embargo, nadie dudará de que dicha noción del tiempo es por completo ajena al hombre medieval y sólo se halla en el discurso de inaccesibles teólogos. Por el contrario, la noción general del tiempo y la conciencia de la duración siguieron rigiéndose en la Edad Media 
por constantes similares a las del mundo antiguo, dominado enteramente por una concepción cíclica, derivada de los ritmos de la naturaleza. Durante la Edad Media, el calendario refejaba, como en la antigüedad, el cambio de las estaciones del año y la sucesión de las tareas agrícolas. A medida que se iba afianzando la cristianización de Europa, el calendario natural pagano, que sólo reflejaba los cambios de la naturaleza, se fue adaptando a las necesidades de la liturgia cristiana. El tiempo agrario, terminó siendo también el tiempo litúrgico.

El hecho de que en la sociedad agraria el tiempo se regulase de acuerdo con los ciclos de la naturaleza, no sólo determinaba la dependencia del hombre de los cambios de los períodos anuales, sino también la estructura específica de su conciencia. En primer lugar, ya que el ritmo de la vida y de las ocupaciones principales de la gente dependían del ritmo natural, no existía la necesidad constante de saber exactamente la hora que era; de hecho, el tiempo era local, pues el día natural variaba de una región a otra; la división acostumbrada del día en partes que se correspondían con las horas canónicas, era totalmente suficiente. De ahi la imprecisión de la medida del tiempo. No se percibía el minuto como parte del tiempo y como parte de la hora. Incluso después de haberse inventado y difundido en Europa el reloj mecánico no tuvo durante mucho tiempo la aguja de los minutos. Las principales categorías temporales de la Edad Media eran el año, la estación del año, el mes y el día, y no la hora y, ni mucho menos, el minuto. El tiempo medieval era, fundamentalmente, prolongado, lento y épico.

En segundo lugar, dominaba enteramente la sensación de presente. El hombre parecía vivir en un eterno presente. Ello era así porque el hombre percibía el tiempo en función de los ritmos naturales y en la naturaleza no hay cambios o en todo caso éstos no eran visibles para los hombres de aquella época. Éstos veían únicamente en la naturaleza fenómenos regularmente repetidos; no eran capaces de vencer la tiranía de la rotación rítmica de aquella. Este perpetuo retorno de las cosas se situaba en el centro de la vida de estos hombres determinando su conciencia y sus comportamientos. Los momentos estelares para éstos no eran las transformaciones, sino las repeticiones. Por ello, sólo adquieren carácter de realidad auténtica los actos consagrados por la tradición y reiterados con regularidad. Se niega el individualismo y la originalidad y llegaba a considerarse un heroismo comportarse como todos, como habían actuado las gentes desde tiempos inmemoriales. En materia de conocimiento científico nada mejor que acudir a las autoridades, a los textos ya consagrados. Un ejemplo muy claro de 


\section{Yolanda Guerrero Navarrete}

esta forma de percibir el tiempo se refleja perfectamente en la noción de nobleza que posee la clase feudal. El deseo de confirmar el prestigio de una familia mediante la referencia a la antigüedad por sus orígenes revela la actitud del hombre medieval hacia el tiempo: en la Edad Media, un hombre con poderes, noble e influyente, es el hombre que tiene tras de sí muchas generaciones, en el que parece condensarse el tiempo del clan, que es a la vez el tiempo histórico.

Pero, si sólo se vive el presente, no es menos cierto que se trata de un presente muy amplio, que engloba pasado y futuro de los que ninguna frontera le separa realmente. A través de la magia se podía volver a los tiempos pasados y era posible influir en el curso futuro de los acontecimientos. Se podía predecir el porvenir y cambiar su contenido porque el tiempo no era, como para nosotros, un concepto apriorístico que existiera al margen de la experiencia y con anterioridad a ésta, venía dado por la experiencia misma y era parte integrante de ella, imposible de separar de la trama de la vida. Por ello, por su íntima relación con la vida, no existían instrumentos para medir el tiempo, el tiempo no existía al margen de los hombres y no era indiferente a su vida y a sus actos. Este presentismo que caracteriza la conciencia de la duración en la Edad Media hace que el pasado se conserve en sus contornos reales en la memoria de los hombres medievales sólo durante fragmentos muy cortos de tiempo. Luego, el pasado se folcloriza.

El carácter agrario, natural, mítico y presentista de la conciencia temporal de los hombres del medievo hizo posible el total control social del tiempo por parte de la Iglesia. El clero establecía y dirigía el curso del tiempo en la sociedad feudal, regulando sus ritmos. El dominio del tiempo eclesiástico podía seguir mientras se mantuviese el ritmo lento, mesurado, de la sociedad feudal. El cálculo en generaciones, en reinados de soberanos, en pontificados, tenía más sentido para los hombres de aquella época que el cálculo exacto de intervalos cortos de tiempo no relacionados con los acontecimientos eclesiásticos y políticos vividos por los hombres. Sin embargo, todo cambió con la aparición de la ciudad que, por poseer un ritmo específico de vida, necesitaba de una medida más rigurosa del tiempo, de un uso más cuidadoso del mismo. Así, la ciudad se convirtió en portadora de una nueva actitud hacia el mundo $\mathrm{y}$, por lo tanto, de una nueva actitud hacia el tiempo. En las torres de las ciudades se instalaron relojes mecánicos que servían de objeto de orgullo para los habitantes de las mismas, pero que satisfacían además una necesidad hasta entonces desconocida: la de conocer el momento preciso del día y de la noche. En la ciudad 
se estaba creando un medio social, cuya relación con el tiempo era completamente distinta a la de los señores feudales o a la de los campesinos. Para los comerciantes el tiempo era dinero. El tiempo se convertía en unidad de medida de trabajo. El tiempo adquiría mayor valor, transformándose en importante factor de producción. La aparición del reloj mecánico, a fines del siglo XIII, supuso una auténtica revolución en el dominio del tiempo social. Con él, el control del tiempo empezó a escapar de las manos del clero, la población urbana se convirtió en dueña de su propio tiempo, tiempo que ya tenía un ritmo específico. Así, la creación de un mecanismo para medir el tiempo acabó por generar las condiciones para la elaboración de una nueva concepción de éste, en tanto que corriente uniforme que podía ser dividida en partes iguales y desprovistas de valor cualitativo. En la ciudad medieval se empieza a separar el tiempo de la vida. Por primera vez el tiempo se desplegó definitivamnete en una línea recta que iba del pasado al futuro pasando por un punto que era el presente. El tiempo presente pasó a ser efímero, irreversible e inaprehensible. El hombre se encontró por primera vez ante el hecho de que el tiempo, de cuya marcha sólo se percataba cuando ocurrían ciertos acontecimientos, no se detenía aunque tales acontecimientos no se produjeran. Paralelamente, el tiempo empezó a considerarse como algo muy valioso y fuente de bienes materiales. El tiempo imponía su propio ritmo, obligando al hombre a actuar con mayor rapidez, a apresurarse, a no dejar escapar un instante.

La relación del hombre medieval con su entorno natural y temporal están determinando el tipo de preguntas que los pensadores de la Edad Media se hacían respecto a lo que llamamos ciencias de la naturaleza. Sus respuestas dependen, en cierto modo, de los postulados epistemológicos de cada momento y de las coordenandas metodológicas y filosóficas de cada período. La Edad Media es, cronológicamente hablando, muy amplia y variada. Por ello, conviene establecer las etapas y evolución del conocimiento científico a lo largo de los diez siglos que abarca eso que nos hemos acostumbrado a llamar Edad Media.

Los griegos inventaron la ciencia natural al buscar la permanencia inteligible e impersonal que subyace en el mundo cambiante y al descubrir la brillante idea del uso generalizado de la teoría científica. Durante la primera Edad Media, el cristianismo occidental, formado en los sistemas de pensamiento helenísticos, se preocupó más por conservar los conocimientos recogidos durante los tiempos clásicos que por intentar interpretaciones originales para las que los tiempos, el sistema de transmisión y creación cultural, no estaban preparados. 


\section{Yolanda Guerrero Navarrete}

Sin embargo, se añadió un elemento nuevo: una actitud activa que inició una época de invención técnica y que iba a tener un efecto importante sobre el desarrollo de aparatos científicos. Posteriormente, con la recuperación de la tradición completa de las ciencias griega y árabe en el siglo XII y principios del XIII, en especial de las obras de Artistóteles y Euclides, nació de la unión del empirismo de la técnica con el racionalismo de la filosofia y de la matemática una nueva ciencia empírica que intentaba descubrir la estructura racional de la naturaleza. Al mismo tiempo, las obras de Aristóteles aportaron un sistema más o menos completo de pensamiento científico. El resto de la ciencia medieval consiste en la elaboración de las consecuencias de esta nueva manera de abordar la naturaleza.

Gradualmente, se percibió que la nueva ciencia no estaba en conflicto con la idea de Providencia Divina, aunque ello condujo a una variedad de actitudes respecto a la relación entre razón y fe. Las contradiciones internas del sistema aristotélico, visibles al contrastarlo con otras «autoridades" o con la propia lógica derivada de la observación empírica de los hechos, condujeron finalmente a críticas radicales del mismo. A la vez, la extensión del uso del experimento y de las matemáticas produjeron un aumento del conocimiento positivo. A principios del s. XVII, el uso sistemático de nuevos métodos de experimentación y de la abstracción matemática produjeron resultados tan llamativos que este movimiento fue denominado "revolución científica». Estos nuevos métodos se expusieron en el siglo XIII, aunque sólo fueron empleados por primera vez con plena madurez y eficacia por Galileo. Así, los orígenes de la ciencia moderna se remontan cuando menos al siglo XIII. Asi, nada más alejado de la realidad que equiparar Edad Media y obscurantismo científico. A lo largo de estos siglos, el desarrollo científico evolucionó por las siguientes etapas: entre los siglos $V y$ XII, se produce, sobre todo, la conservación del saber antiguo, produciéndose una tímida primera elaboración puramente occidental del mismo. En los siglos XII y XIII Europa recupera la tradición científica griega a través de la elaboración sintética de la misma realizada previamente en el mundo árabe. En el siglo XIII Europa elabora su sintesis, iniciando una profunda revolución del método científico. A lo largo de los siglos XIV y XV se producen las primeras críticas al sistema escolástico, sentandose las bases de la revolución cientifica del XVII.

$\mathrm{El}$ mundo medieval arranca de la ruina de la civilización romana. En el siglo VI, sólo las abundantes bibliotecas que aún existen en los antiguos territorios ofrecen la posibilidad de conseguir una cierta formación y de aproximarse a los autores clásicos. Así, la herencia 
científica del occidente latino debía estar limitada casi exclusivamente a fragmentos del saber grecolatino tal y como había sido éste conservado en las compilaciones de los enciclopedistas latinos. La obra más influyente en este sentido fue La Historia natural de Plinio. La primera labor del occidente medieval, fue la de conservación de estos fragmentos. A ello dedicaron su vida hombres como Boecio o Casiodoro en Italia, Isidoro de Sevilla en la España visigoda o Gregorio de Tours en Francia.

El siglo VII abre una nueva época: las diferencias que han separado desde el s. III al oriente griego y el occidente latino se acentúan y ambos se introducen en el camino de una ignorancia recíproca nada enriquecedora para la cultura. Asimismo, cuando la aristocracia occidental pierde su prestigio y su papel político, fusionándose con los nuevos elementos germánicos, la cultura clásica habría estado condenada a desaparecer si las letras cristianas no hubieran intentado utilizarla para alimentar la cultura religiosa. En estas circunstancias se produjo un siglo más tarde la expansión islámica. Ésta asestó un grave golpe a la cristiandad occidental, en realidad mucho más grave que el previo de las invasiones germanas, pues significó el cierre de la principal fuente de conocimientos griegos para los eruditos occidentales durante siglos debido a la intolerancia y recelos mutuos. En estas condiciones de aislamiento intelectual, occidente se mostró incapaz de hacer ninguna aportación original al conocimiento científico. Todo lo que quiso y pudo hacer fue conservar la colección de datos e interpretaciones conservada por los compiladores bajoimperiales. Los centros de conservación del saber antiguo fueron los cenobios monásticos. Su paciente labor fue la que hizo posible los sucesivos "renacimientos" del período: el irlandés (s. VII) en Northumbria en tiempos de Beda el Venerable o el carolingio en el siglo IX. A esta atonía del conocimiento científico contribuyó mucho el sistema de pensamiento vigente en estos primeros siglos de la Edad Media, que, como vimos anteriormente, hacía de la naturaleza algo pecaminoso e imperfecto.

Sin embargo, algo había empezado a cambiar mucho antes de que se recibiera en Occidente toda la tradición clásica greco-árabe. Ello fue así como resultado, primero, de las primeras observaciones empíricas del mundo por parte de los occidentales y las contradiciones que éstas arrojaban con respecto a las teorías mantenidas por las fuentes tradicionales del conocimiento científico altomedieval. En segundo lugar, la actitud hacia la naturaleza empezó a cambiar con las tranformaciones operadas en la perspectiva filosófica a las que está íntimamente asociado el nominalista del siglo XII Roscelino y su discípulo Pedro Abelardo. La disputa de los universales entablada a finales del s. XI por no- 
minalistas y realistas, condujo a un mayor interés por lo concreto y material en cuanto tal y no ya como mera sombra de una idea eterna. La realidad empezaba a cobrar sentido por sí misma y no como reflejo de la vida eterna. Así, en los círculos de París, Chartres, norte de Francia, va a surgir la primera explicación del universo en términos de causas naturales que, aunque todavía muy influida por la filosofia platónica, iba a pervivir largo tiempo en la europa medieval.

Sin embargo, las escuelas del norte de Francia entraron en contacto en el siglo XII con las escuelas de traductores que trabajaban sobre textos griegos y árabes en Toledo y sur de Italia y fue en el norte de Francia donde se empezó a recibir por primera vez la astronomía ptolemaica y la física aristotélica. Así, el sistema de pensamiento representado por Chartres iba a quedar definitivamente anticuado casi inmediatamente después de su primer enunciado. Pronto sería reemplazado por los que siguieron a árabes y griegos en la búsqueda de causas y explicaciones para los fenómenos naturales. La nueva ciencia que comenzó a infiltrarse en la cristiandad occidental en el s. XII era predominantemente árabe por la forma, pero estaba basada en las obras de los antiguos griegos. En el s. X casi todos los textos de la ciencia griega estaban ya traducidos al árabe. La reactivación de las relaciones comerciales entre occidente y el Islam permitió la gradual penetración de la cultura previamente recopilada por los árabes. Los centros principales de esta transmisión fueron Sicilia y, sobre todo, España. Toledo fue conquistada por Alfonso VI en 1085 y a mediados del XII se convirtió en el centro español de traducción del árabe al latín. El modus operandi habitual era que dos estudiosos trabajaran en tándem, generalmente se trataba de un judío y un eclesiástico. El primero, conocedor de la lengua árabe, traducía en voz alta de ésta al romance y el segundo elaboraba posteriormente un borrador en latín. La tarea no era fácil, debido a lo intrincado del tema y a la complicada terminología técnica. Con frecuencia las traducciones eran literales y a menudo palabras cuyo significado no era totalmente entendido eran transcritas simplemente del árabe o del hebreo. Muchas de estas palabras han subsistido hasta el presente: circonio, alambique, sorbewte, elixir, talco, cifra, álgebra, etc. Todo ello hizo que muchas de las primeras traducciones debieran ser revisadas ya en el siglo XIII.

Los conocimientos griegos más importantes transmitidos por los árabes fueron las obras de Aristóteles, Ptolomeo y Galeno. Estos constituían un sistema completo racional que explicaba el universo como un todo en términos de causas naturales. Aristóteles, además incluía explicaciones más completas sobre todas las cosas existentes, desde 
la materia prima hasta Dios. Por eso, este último, entró en grave conflicto con el propio sistema explicativo vigente en Occidente, el neoplatónico agustinista. Algunas de las teorías aristotélicas eran abiertamente contradictorias con este último: por ejemplo, defendía que el mundo era eterno y eso, obviamente, entraba en serio conflicto con la concepción cristiana de un Dios creador. Por ello, la obra de Aristóteles fue prohibida por las autoridades eclesiásticas en un primer momento. Sin embargo, su impacto fue tan importante en el clima intelectual de Occidente, que todos los esfuerzos de la Iglesia fueron inútiles. Aristóteles respondía a casi todas las cuestiones que venían planteándose los pensadores occidentales desde el s. XI. El problema para la ciencia había sido siempre el mismo desde la difusión del cristianismo: cómo entender la relación que hay entre lo que afirman las autoridades científicas y lo que ha sido revelado por Dios. La Alta Edad Media negó validez a las primeras siempre que entraran en contradicción con la segunda. A raíz de la incorporación a Occidente del pensamiento aristotélico se inició un fructífero e intenso intento para encontrar una conciliación entre la filosofia aristotélica y la teología cristiana. En Europa, las posturas radicales (averroistas latinos, partidarios de seguir a Aristóteles al pie de la letra) no tuvieron éxito, triunfó, en los siglos XIII y XIV la actitud moderada representada por Santo Tomás que condujo a una salomónica división entre filosofia y teología, razón y fe que garantizaba a cada cual su campo de trabajo. Era mejor, como afirmaba Tomás de Aquino, seguir a los apóstoles y a los padres de la Iglesia en materia de fe y costumbres y a Galeno, Hipócrates o Aristóteles en cuestiones médicas y físicas. El triunfo de la opción moderada hizo posible la paulatina asimilación del aristotelismo y, además, gracias a la condena de las actitudes extremas averroistas, se otorgó a los pensadores de suficiente libertad para hacer hipótesis sin tener en cuenta la autoridad de Aristóteles, para desarrollar la actitud mental empírica trabajando dentro de un armazón racional y hacer así posible la ampliación de los hallazgos científicos. Si la labor de asimilación y adaptación de Aristóteles al pensamiento cristiano condujo a la gran síntesis del pensamiento medieval y a la elaboración de los principales contenidos de la ciencia medieval, no es menos cierto que la sistemática crítica del sistema aristotélico que impuso el triunfo de la filosofia nominalista a partir del siglo XIV, significó el comienzo de las bases de la llamada "revolución científica».

El sistema aristotélico constituyó la base de toda la ciencia medieval a partir del s. XIII. Sin embargo, no fue recibido en Europa de forma meramente pasiva. La actividad intelectual que ya se había manifestado 
incluso antes del siglo XII en el campo de la filosofía y de la técnica se aplicó inmediatamente para detectar e intentar resolver las contradicciones que existían dentro del mismo sistema aristotélico. Entre Aristóteles y otros autores, como Ptolomeo, Averroes o Avicena, primero; entre las autoridades y los hechos observables, después. Los estudiosos europeos occidentales intentaban hacer inteligible el mundo natural y se apropiaron el nuevo conocimiento como algo maravilloso, pero no definitivo, por lo que continuamente se introducían innovaciones y modificaciones en el conocimiento preexistente. Estos cambios se realizaron en su mayor parte como resultado de la extensión gradual de la observación, de la experimentación y del uso de las matemáticas, y fueron posibles en gran medida como resultado de hábitos adquiridos en la tecnología. Iban a producir, ya en los siglos XIV y XV el derrocamiento de todo el sistema de la Física de Aristóteles. Gran parte de estos cambios y críticas se iban a producir dentro del mismo sistema de pensamiento científico aristotélico. Desde Grosetesta hasta Galileo, él ocupó el centro de la escena, proporcionando muchas de las armas con las que fue atacado.

En la actualidad, muchos estudiosos están de acuerdo en que el humanismo del s. XV, que surgió en Italia y se extendió hacia el norte, significó una interrupción en el desarrollo de la ciencia. El renacimiento de las letras distrajo la atención por la materia en favor del estilo literario y al volverse sobre la antigüedad sus devotos pretendieron ignorar los progresos científicos de los tres siglos anteriores. Así, hacia finales del siglo XIV llegó a su término el brillante período de la originalidad escolástica. Durante el siglo y medio siguiente, todo lo que París y Oxford produjeron sobre astronomía, física, medicina o lógica fueron monótonos epítomes de obras anteriores. Ahora el interés y la originalidad intelectual estaban orientados hacia la literatura y las artes plásticas más que hacia la ciencia de la naturaleza. Por ello, aun salvando las enormes distancias que separan el s. XIII del XVII en materia científica, puede considerarse a la ciencia de este último siglo como la segunda fase de un movimiento intelectual que comenzó cuando los filósofos del s. XIII leyeron y aismilaron las traduciones latinas de los grandes autores científicos de la Grecia clásica y del Islam.

\section{Los contenidos de la ciencia y los progresos de la técnica en la Edad Media ${ }^{5}$}

En Cosmología y Astronomía la Edad Media heredó de la antigüedad dos modelos explicativos del universo. El contenido en la Física de 
Los contenidos de la ciencia y los progresos...

Aristóteles, que defiende una explicación física de los fenómenos cosmológicos y el matemático de Ptolomeo, recogido en un tratado que en la Edad Media recibió el nombre latinizado de Almagesto. Cuando los pensadores medievales se vieron en la necesidad de escoger entre uno u otro percibieron que si el sistema ptolemaico era el único que permitía la elaboración y aplicación de tablas astronómicas, su explicación de excéntricos y epiciclos era inadecuada para describir las órbitas reales de los planetas y explicar las causas de sus movimientos. Empezó a demandarse una explicación a la vez física y matemática compatible y adecuada.

La primera respuesta a estas contradiciones se produjo en el sentido aristotélico de ciencias verdaderas (física) y ciencias arbitrarias o abstractas (matemática). Para Tomás de Aquino, las hipótesis físicas pueden ser consideradas verdaderas necesariamente, mientras las matemáticas, como toda abstracción, sólo se adecúan aparentemente a los hechos. Sin embargo, poco a poco se fue imponiendo la otra idea. Hacia mediados del siglo XIII se afirmaba ya que las hipótesis astronómicas debían ser elaboradas en primer lugar con la idea de explicar los hechos observados y que la evidencia experimental debía decidir la controversia entre los físicos aritotélicos y lo matemáticos ptolemaicos. Asimismo, cuando había un número de hipótesis posibles debía escogerse la más sencilla. Hacia finales del s. XIII, el sistema concéntrico aristotélico había sido completamente desechado en París a la luz de la experiencia práctica y el sistema ptolemaico fue universalmente aceptado. No acabaron, sin embargo, las controversias. En el siglo XIV, la innovación más radical fue la de considerar que era la tierra la que giraba alrededor del sol y no a la inversa (Juan de Buridán, Nicolás de Oresme).

Con respecto a la astronomía práctica, la Edad Media se vió muy limitada instrumentalmente. Básicamente no conoció otro instrumental astronómico que el astrolabio, muy perfeccionado por los árabes y el cuadrante. Pese a ello, consiguieron medidas bastante exactas sobre ciertas latitudes e incluso se aventuraron hacia el cálculo de longitudes, aunque un cálculo preciso de éstas requiere de una medida exacta del tiempo, cosa que la Edad Media se hallaba lejos de lograr.

La Meteorología y la Optica formaban en el siglo XIII una disciplina única y hetereogénea debido a que trataban fenómenos que se suponía ocurrían en las regiones aristotélicas de los elementos fuego y aire situados entre la esfera de la luna y el globo terráqueo. En el campo de la meteorología los avances medievales fueron limitados. Siguió considerándose a los cometas, etc. como fenómenos pertenecientes a la región sublunar. Las medidas más exactas de sus posiciones ya en 
el siglo XVI prorcionarían uno de los argumentos más elocuentes en contra de todo el sistema astronómico aristotélico. Asimismo, se hicieron observaciones sobre el clima e intentos para predecirlo. Sin embargo, fue la óptica la que obtuvo mayores progresos durante la Edad Media. Como en la astronomía, la Edad Media siempre se debatió entre una óptica física y una ótpica matemática.

El primer europeo importante en el campo de la óptica fue Grosetesta, pero sus fuentes, además de griegas eran, sobre todo, árabes. Autores como Alkindi, Alhazen, Avicena y Averroes. A los avances árabes en materia de refracción e incidencia de la luz Grosetesta sumó un intento de explicar la forma del arco iris mediante la refracción de la luz en una lente esférica. Su discípulo, Roger Bacon perfeccionó el conocimiento anatómico del ojo, trató de mejorar la visión con lentes plano-convexas y dejó jugar libremente a su imaginación en otros terrenos: agrandar objetos pequeños indefinidamente con dispositivos de lentes o espejos curvados, aproximar objetos lejanos. Creía que Julio César había montado espejos en la Galia para vigilar Inglaterra. Afirmaba que con lentes se podía hacer que el sol y la luna parecieran descender sobre la cabeza de los enemigos provocando el espanto entre la masa ignorante, etc.. Entre fines del s. XIII y comienzos del XIV, el alemán Teodorico proporcionó una explicación del arco iris como producido por la luz que caía sobre las gotas esféricas de lluvia, siendo refractada en cada gota, reflejada en su superficie interior y refractada hacia fuera de nuevo. Explicación aceptada en la actualidad y atribuida erróneamente a Descartes, al que se debió solamente la superioridad de la demostracion matemática.

$\mathrm{Al}$ margen de la luz, las únicas causas inanimadas del movimiento local estudiadas en la Edad Media fueron la mecánica y el magnetismo y las únicas causas mecánicas naturales fueron la gravedad y la ligereza. Al igual que en otros campos de la ciencia, la Mecánica y la Fisica aristotélicas constituyen aquí también el punto de partida. Punto de partida que fue sometido a un fecundo exámen lógico y empírico a partir del s. XIII. Esto llevó, en la siguiente centuria a un crítica radical de sus ideas dinámicas y de sus consecuencias físicas, como la imposibilidad del vacío, crítica que preparó el camino para el inmenso esfuerzo intelectual por medio del cual Galileo y sus seguidores en el s. XVII escaparon de los principios aristotélicos y establecieron la mecánica matemática, rasgo más distintivo de la revolución científica. Sin embargo, todavía en el siglo XIII, lo más improtante no fue la dinámica, sino la estática (o mejor cinemática, estudio de la velocidad del movimiento) lo que llamó más la atención, en concreto la gravedad. 
A este respecto las conclusiones de la escuela de Jordano Nemorarius (s. XIII y XIV), resumidas por Blaso de Parma en el s. XV y extensamente utilizadas por Leonardo da Vinci, se convertirían en el punto de partida de algunos de los más espectaculares progresos en la mecánica producidos en los s. XVI y XVII.

La otra fuerza motriz natural que junto con la gravedad ocupó principalmente la atención de los físicos en el siglo XIII fue la atracción magnética. Éste fue el tema de lo que pasó a convertirse en uno de los más llamativos ejemplos de investigación experimental planificada anterior a finales del XVI: la obra de Petrus Peregrinus, Epistola de Magnete, escrita como carta a un paisano picardo del autor mientras éste esperaba al ejército de Carlos de Anjou que sitiaba las murallas de Lucen en el sur de Italia. Antes de las investigaciones e Peregrinus se conocían algunas propiedades del imán. El hecho de que atraía el hierro no le era desconocido a Tales y fue más tarde citado como ejemplo clásico de la virtud oculta. Los chinos conocían su tendencia a orientarse de norte a sur y esta propiedad fue adaptada —quizá por los musulmanes que estaban en contacto marítimo con ellospara inventar la brújula. Pese a todo, la explicación del imán de Peregrinus no se acercó a la aceptada en la actualidad puesto que siguinedo los principios aristotélicos afirmó que el imán apuntaba hacia los polos de los cielos sobre los que giraba la esfera celeste.

La Geologia en el s. XIII se interesaba, sobre todo, por los cambios en las posiciones relativas a las principales masas de los elementos agua y tierra que formaban el globo terráqueo en el centro del universo, por el origen de los continentes y de los océanos y de las montañas y ríos y por la causa productora de los minerales y de los fósiles. Sus tres fuentes principales fueron: la Meteorológica de Aristóteles, $\mathrm{y}$ dos tratados árabes, uno de ellos anónimo escrito en el siglo $\mathrm{X}$ y el De mineralibus de Avicena, tambén de este siglo.

Los griegos habían hecho de la erosión el principal factor a tener en cuenta en la formación de los elementos de la geología terrestre. Los tratados árabes rechazaron esta explicación. Avicena aceptaba la teoría de que antiguamente la tierra había estado cubierta por las aguas y propuso la idea de que la emergencia de la tierra firme y a formación de las montañas se debía no a la erosión de las aguas sino, unas veces a la sedimentación marina y otras, la mayor parte le las veces, a la erupción de la tierra a causa de terremotos prorocados por el viento aprisionado bajo tierra. Una vez formadas las nontañas eran erosionadas por el viento y el agua y seguían siendo lestruídas progresivamente. El primer gran geólogo latino fue Alberto 


\section{Yolanda Guerrero Navarrete}

Magno quien aceptó las teorías aristotélicas y árabes sobre geología aun llegando a conclusiones propias. Dió descripciones originales de muchas piedras preciosas y de minerales, aceptando las virtudes mágicas de las piedras. Describió una explicaicón de los rios que fue aceptada hasta el s. XVII según la cual existía una corriente continua del agua desde el mar a través de cavernas subterráneas y por el interior de las montañas hacia arriba, de donde brotaba de nuevo como río hacia el mar.

En el s. XIV Juan Buridán y Alberto de Sajonia desarrollaron una nueva esplicación de la formación de la tierra y de las montañas, basándose en la teoría de la gravedad. Defendían que la tierra estaba en su lugar natural cuando su centro de gravedad coincidía con el centro del universo. El centro del volúmen de la tierra no coincidía con su centro de gravedad porque el calor del sol hacía que parte de la tierra se expandiera y se elevara sobre las aguas circundantes que, al ser fluidas, permanecían con su centro de gravedad en el centro del universo. El desplazamiento de la tierra respecto del agua originaba la aparición de la tierra firme, dejando otras partes sumergidas y justificaba la hipótesis - refutada más tarde por Cristóbal Colónde que un hemisferio de océano equilibraba un hemisferio de tierra. La tierra que había emergido era entonces erosionada por las aguas, formando valles y haciendo aparecer montañas. Era la única función que se atribuía al agua; junto con el calor del sol, ello desplazaba de nuevo el centro de gravedad de la tierra, el cual describía así pequeños movimientos continuos con el fin de coincidir con el centro del universo y provocaba cambios continuos en los límites de la tierra y el mar. La erosión del agua arrastraba la tierra al mar, cuyo fondo, debido a los movimientos del centro de gravedad de la tierra, se movía gradualmente para cruzar el centro del globo y reaparecer finalmente de nuevo en tierra firme por el otro lado.

La química medieval comenzó como un arte empírico, pero alrededor del siglo XIII había adquirido ya un cuerpo considerable de teoría, cuya finalidad era explicar el tipo de cambio en que estaba interesada la química, a saber, cambios de cualidad y de sustancia en las sustancias inanimadas de la región terrestre aristotélica. Este edificio teorético llegó a entrelazarse de forma inextricable con la alquimia, asociación que iba a determinar el carácter de la investigación química durante siglos. La alquimia tenía espíritu empírico, pero desembocó en un callejón sin salida al concentrar su atención más en los cambios de color y apariencia que en los cambios de masa. De este modo, mientras la práctica alquímica produjo una gran cantidad de información útil, 
la teoría alquímica tendrá poco que ofrecer a la nueva química que comenzó a surgir en el XVII.

Las fuentes principales de la práctica alquímica en el s.XIII fueron, a parte de la experiencia práctica transmitida de generación en generación, las traducciones latinas de varios tratados griegos y árabes sobre los tintes, la pintura, la fabricación de cristal y otros procesos decorativos, la pirotecnia, la materia medica, la minería y la metalurgia. Los pocos manuscritos químicos latinos que quedan anteriores al s. XII son enteramente de carácer práctico. Desde alrededor de 1144 , cuando Roberto de Chester tradujo el Liber de Compositione Alchemiae la alquimia árabe comezó a penetrar en la Europa occidental.

$\mathrm{El}$ origen de la alquimia parece haber estado en la unión, trás el período helenístico, de la práctica de los trabajadores egipcios del metal con las teorías de la materia de los gnósticos y de los neoplatónicos alejandrinos, que eran fundamentalmente aristotélicos.. Estas ideas calaron en la química desde el s. III hasta el XVII y no era raro que incluso las operaciones prácticas de laboratorio se describiesen en un oscuro lenguaje simbólico, quizá para burlar a otros y mantenerlos ocultos. Esta oscuridad mas o menos deliberada produjo dos resultados desafortunados. En primer lugar, retrasó el progreso, ya que cada trabajador en este campo se hallaba en la ignorancia o al menos en la incertidumbre de lo que otros hacían sin poder aprovecharse de sus errores ni de sus descubrimientos. En segundo lugar, permitió que cualquier embaucador que hablara con la suficiente oscuridad se presentara a sí mismo como un serio trabajador.

Los incios de la alquimia medieval se deben a los árabes. En Persia, éstos se enconrtraron con lo que quedaba de la tradición alquímica griega y quedaron fascinados. Máxime, cuando en el año 670, al asediar Constantinopla fueron rechazados por el fuego griego, una mezcla química que ardía con violencia, no podía ser destruida con agua y que destruyó los barcos de madera de la flota árabe. De acuerdo con la tradición, fue preparado pro Calínico un alquimista que había huido de Egipto precediendo a los ejércitos árabes. Cuando los árabes heredan la alquimia griega, el elemento mágico había llegado mucho más lejos que el práctico, sin embargo, éstos potenciaron su aspecto práctico. Quizá de todos los que más influyeron fue Jabir ibn Hayyan que en su búsqueda de la piedra filosofal describió procesos como la destilación y el uso de baños de arena y de agua, la cristalización, la calcinación, la solución, la sublimación, la reducción, la preparaciòn del acero, los tintes, barnices y tintes para el cabello. Junto con Rhazes y Avicena fueron los químicos más influyentes en la Europa occidental. 
Ésta heredó tanto la alquimia mágica como la práctica. A pesar del escepticismo de algunos autores y de ciertas descripciones de prácticas de laboratorio, no se realizó ningún progreso de química teórica sobre los árabes antes de Paracelso, en el s. XVI, sin embargo, en química práctica se hicieron algunas aportaciones interesantes ya a fines del período medieval (sobre todo en materia de alambiques y destilación). Los aspectos tanto mágicos como prácticos de la alquimia florecieron vigorosamente en Occidente durante la Edad Media. La búsqueda de una fórmula por los alquimistas que pudiera porprocionar salud y eterna juventud, riquezas y poder es el origen de leyendas como la del doctor Fausto. El primer alquimista importante fue Alberto de Bollstadt (1200-1280) (San Alberto Magno) quien en la faceta química de su producción describió el arsénico de forma tan clara que a veces recibe el crédito de su descubrimiento, a pesar de que esta sustancia era, sin duda, conocida por los alquimistas anteriores, al menos en forma impura. Roger Bacon (1214-1292) describió por primera vez la pólvora. Una vena más mística de la alquimia se encuentra en las obras de los españoles Arnaldo de Villanova (1235-1311) y Ramón Llull (1235-1315). Estos escritos se refieren fundamentalmente a la transmutación. No se conoce, sin embargo, el nombre del más importante alquimista, que firma sus obras con el sinónimo Geber, sólo se sospecha que posiblemente se tratara de un español que escribió hacia el año 1300. Fue el primero en describir el ácido sulfúrico que, junto con el aire, el agua, el carbón y el petróleo es la sustancia más importante de entre las utilizadas por la industria química en nuestros días. También describió la formación de ácido nítrico fuerte. Este descubrimiento de los ácidos minerales fuertes puede conceptuarse como el más importante avance químico desde la obtención del hierro unos tres mil años antes. Con estos ácidos fuertes, los europeos estuvieron en disposición de disolver muchas sustancias y llevar a cabo reacciones químicas, que para los griegos y árabes estuvieron vedadas. De hecho, los ácidos minerales fueron mucho más importantes para el bienestar de la humanidad de lo que hubiera sido el oro si hubiese sido posible su producción por transmutación.

En el siglo XIV, trás un comienzo prometedor, la alquimia comenzó a degenerar por tercera vez, como ya lo hizo entre griegos y árabes. La caza del oro se convirtió en un campo casi exclusivo de los charlatanes, aunque improtantes estudiosos. Una vez más, se prohibió la alquimia. El papa Juan XXII, autor por su parte de obras alquímicas, decretó la excomunión en 1317 y mientras alquimistas modestos forzados a trabajar en la clandestinidad se hicieron más oscuros que nunca, el chantaje químico floreció como siempre. 
Parte de los principios que iluminaban la química eran aplicables a la biología y a la medicina, aunque esta última se consideró más una técnica. También aqui el punto de partida es Aristóteles. El tema de la biología del s. XIII era, lógicamnete, las actividades de los diferentes seres que formaban la escala de la naturaleza viviente. Y el modo en que eran concebidos abría el camino, naturalmente, para las explicaciones tanto teleológicas como mecánicas. Hasta el s. XIII, el interés principal de los latinos por la botánica había sido médico; y el interés por la zoología, moral y didáctico. De hecho, las mismas actitudes caracterizaron mucho de la historia natural hasta el siglo XVII. Por ejemplo, Alejandro Neckam (1157-1217) autor de una enciclopedia titulada De Naturis Rerum, creía que la caída del hombre había tenido efectos físicos sobre la naturaleza, causando las manchas de la luna, el estado salvaje de los animales, los insectos nocivos, los venenos y las enfermedades animales. Él no pretendía ser un científico, su finalidad era solamente didáctica.

Los mejores tratados de zoología son, sin duda, las obras de cetrería. Pero no eran el único deporte que rindió servicios a la zoología. Las casas de fieras que los reyes, príncipes e inlcuso las ciudades tenían para su diversión - como las luchas de osos-o como curiosidad, eran descendientes de las de la antigüedad. La que transportaba Federico II con él en sus viajes, incluso a través de los Alpes, incluía elefantes, dromedarios, camellos, panteras, leones, leopardos, halcones, buhos, monos y la primera jirafa que se cita como aparecida en Europa. La primera gran casa de fieras en el Norte fue la establecida en el s. $\mathrm{XI}$, en Woodstock por los reyes normandos. En el siglo XIV, los papas de Aviñón mantenían una gran colección de animales exóticos.

Uno de los intereses de la biología del s. XIII era la reproducción de los seres vivos. En este campo se siguieron, al menos en esta centuria, las teorías aristotélicas. Alberto Magno, distinguió, al igual que Aristóteles, tres tipos de reproducción: reproducción sexual, en la que los principios masculino y femenino estaban, bien separados como en los animales superiores, bien unidos, como en las plantas y otros animales, como las abejas; reproducción por capullo, como en algunas almejas; y generación espontánea, como en algunos insectos, anguilas y, en general, las criaturas inferiores. Los sexos de las plantas no fueron distinguidos claramente. Alberto, como Aristóteles, rechazó la teoría hipocrática, defendida también por Galeno, de que ambos padres contribuían a la forma. Aristóteles había defendido que la hembra proporcionaba solamente la materia (que él creía era la menstruación en los mamíferos y la yema del huevo en las aves), a partir de la 


\section{Yolanda Guerrero Navarrete}

cual la forma inmaterial masculina construía el embrión. Alberto estaba de acuerdo con esta idea, pero siguió a Avicena al defender que la materia porducida por la hembra era una semilla, distinta de la menstruación o yema del huevo, que decía era solamente alimento. Identificó erróneamente esta semilla con la clara del huevo. El espermatozoide no fue descubierto por supuesto hasta el descubrimiento del microscopio. Alberto defendía que la causa de la diferenciación del sexo era que el calor vital del macho era capaz de mezclar el exceso de sangre en semen, dándole la forma de la especie, mientras que la hembra era demasiado fría para efectuar este cambio sustancial. Todas las otras diferencias entre los sexos eran secundarias a ésta. En el siglo XIII, Gil de Roma escribió un tratado de embriología humana en el cual discutía el desarrollo del feto y el momento en que se insufla el alma. Sobre este punto había mucha controversia y uno de los que participaron en la discusión fue Dante quien propuso la idea de San Agustín y Averroes de que el alma era engendrada juntamente con el cuerpo, pero que se manifestaba solamente con los primeros movimientos del feto.

La rama de la biología donde hubo descubrimientos más importantes en los s. XIV y XV fue la anatomía humana. Las fuentes principales de la anatomía latina fueron Galeno y Avicena, cuyas obras estaban en parte basadas en el primero. Las ideas de Aristóteles fueron desechadas por las de Galeno habitualmente más exactas. Las ideas anatómicas de Galeno estaban basadas en las disecciones de cuerpos humanos y animales y en la obra de algunos predecesores suyos de la antigüedad. Según Galeno, el cerebro (y no el corazón como decía Aristóteles) era el centro del sistema nervioso, y las funciones vitales se explicaban por medio de los tres espíritus (spiritus o pneuma) y los cuatro humores hipocráticos, que correspondían a los cuatro elementos. El equilibrio entre estos cuatro humores - sangre, flema (o pituita, que se encuentra en el cuerpo pituitario), bilis negra ( o melancolia, que se encuentra en le bazo) y bilis amarilla (que se encuentra en la vejiga biliar) _ era necesario para el funcionamiento saludable del cuerpo; pero las mismas funciones vitales eran provocadas por la producción y los movimientos de los tres espíritus: el "espíritu natural» del hígado, el "espíritu Vital" del corazón y el "espíritu animal" del cerebro. Éstos procedían, en último término, del alimento y del aire introducido en los pulmones por el acto de la respiración, cuando Gelenı) afirmaba que el principio de la vida entraba en el cuerpo animal. Esta teoría fisiológica dominó enteramente las ideas sobre la significación de las estructuras anatómicas y sus conexiones hasta el s. XVI!. 
Los científicos medievales que leyeron por primera vez las obras de Galeno fueron capaces de añadir poca cosa que fuera original, sólo insistieron que el conocimiento de la anatomía era esencial para la buena práctica de la medicina y cirujía. En el Salerno del s. XII parece que la disección del cuerpo de animales y humanos era una parte de la formación médica. A partir de aquí, las descripciones anatómicas resultado de disecciones cada vez más generales se fueron multiplicando. A Mondino de Luzzi se debe la introducción de la práctica regular de disecciones de cadáveres con fines didácticos. Aunque sus disecciones no pretendían aprender anatomía sino adquirir práctica de cirujanos, inauguró una práctica que iba a hacer avanzar mucho los conocimeintos de anatomía humana y paralelamente la técnica de la disección.

El desarrollo teórico y práctico de la anatomía es sólo uno de los aspectos de los avances en materia médica realizados por el occidente europeo en la Edad Media. De las facultades superiores de Teología, Leyes y Medicina, en las universidades medievales, solamente en las de medicina era posible disponer de un aprendizaje ulterior en la ciencia de la naturaleza después del grado en artes y muchos de los miembros más destacados de la ciencia habían estudiado medicina. Sin duda, en el campo de la medicina empírica, los médicos medievales encontraron soluciones a algunos problemas importantes y establecieron la actitud científica fundamental que caracteriza la práctica médica moderna.

Tras la caída del Imperio romano, la medicina occidental fue en gran parte medicina popular, pero se salvó cierto conocimieto de la medicina griega gracias a autores como Casiodoro e Isidoro de Sevilla y a los monasterios benedictinos. Se conocían resúmenes latinos de partes de Hipócrates, Galeno y Dioscórides; y algo de la tradición ginecológica de Sorano (s. II d.C.) sobrevivió en los libros de comadronas. En la época carolingia tuvo lugar un renacer del saber médico en Chartres y en otras escuelas; en el s. X aparecieron los Leech Books en la Inglaterra anglosajona y en el s. XI las obras de Hildegarda de Bingen en Alemania, pero el auténtico renacimiento de la medicina occidental comenzó en el s. XI, cuando la escuela de medicina de Salerno que había aparecido progresivamente quizá un siglo o dos antes, empezó su actividad reconocida. Aquí hay que destacar la obra del llamado Constantino el Africano (1015-1087), que ejerció como traductor y en cuya obra se comprueba fácilmente la influnecia árabe. A partir de él y con posterioridad a él, los escritos médicos demuestran un claro influjo de la terminología árabe. La obra de Constantino abarca: fundamentos y exponentes de la medicina latina; la medicina de la antigüedad clásica; grandes tratados árabes; escritos menores de mé- 


\section{Yolanda Guerrero Navarrete}

dicos islámicos. Es de lamentar que su obra nos haya llegado totalmente fragmentada e incompleta. En el s. XII, también Montpellier comenzó a adquirir importancia como centro médico y en el s. XIII, las escuelas de medicina de las universidaes de Montpellier, Bolonia, Padua y Paris sobrepasaron gradualmente a Salerno. La enseñanza de la medicina en estas escuelas se basaba en varias obras de Galeno y de Hipócrates y de médicos árabes y judíos cuya traducción al latín fue la principal causa del renacimiento de la medicina occidental desde los siglos XII y XIII. Las obras más importantes fueron el Canon de la Medicina de Avicena, la obra clásica sobre las fiebres de Isaac Israeli y las obras de Rhazes donde se describían enfermedades como la viruela y la rubeola. La obra del español Abulcasis proporcionó el primer manual de cirujía y a través de las obras de Hunain ibn Ishaq y de Ali Abbas (s. XI) se conoció la oftalmología árabe. Otras obras importantes fueron las del bizantino del s. VII Teófilo sobre el pulso y la orina, cuyo exámen era el método de diagnóstico más común en la Edad Media.

Los tratamientos medicinales en la Edad Media, cuando no se limitaban simplemente al método hipocrático de que el enfermo guardara cama y dejar a la naturaleza seguir su curso, estaban basados en las plantas. En la medicina griega, la teoría fisiológica subyacente al empleo de las plantas era que la enfermedad se debía a un desequilibrio entre los cuatro humores, de forma que se administraban medicamentos "refrescantes" para compensar el exceso de calor en el enfermo, medicamentos secantes para contrarrestar la excesiva humedad, etc. La Edad Media heredó un conocimiento muy antiguo sobre los efectos de las plantas a los que los árabes añadieron algunas procedentes de la India y China. Los médicos occidentales hicieron más aportaciones. En el s. XII se recomendaba "cuando se quería serrar o cortar a un hombre que se mojara un trapo en la llamada spongia soporifera (mezcla a partes iguales de opio, mandrágora, beleño molidos y agua) y se la aplicara en las narices. Experimentos modernos demuestran que esta mezcla no podía ser demasiado anestésica y se hicieron experimentos durante la Edad Media para mejorarlo incluyendo entre ellos el uso de vapores de alcohol, ya en el XVI.

Una rama de la medicina en la que el empirismo de la mente medieval se mostró acertada fue la observación de los efectos de diferentes enfermedades. A ello contribuyeron en gran medida los CON. SILIA o relatos de casos clínicos que cuando se basaban realmente en la experiencia fueron muy útiles y proporcionaron descripciones excelentes de los síntomas y curso de enfermedades como la peste 
bubónica y neumónica, la difteria, la lepra, la tisis, la rabia, la diabetes, la gota, el cáncer, la epilepsia, etc. Muchos de estos consilia fueron impresos al final del s. XV y en el XVI. Son el origen de los libros de historias clínicas modernos. La limitación principal de los médicos medievales fue, de hecho, no el que no pudieran diagnosticar la enfermedad, sino el que frecuentemente no pudieran curarla. Poseían una idea muy limitada de la fisiología normal o patológica o de las causas de la mayor parte de las enfermedades y, en ocasiones, eran engañados por la costumbre, que provenía de la filosofia aristotélica, de considerar cada síntoma por separado e incluso las heridas como manifestaciones de una forma específica independiente. Los casi veinte opúsculos escritos en varios lugares por los médicos durante la gran epidemia de peste medieval del siglo XIV, muestran las características que se encuentran habitualmente en la medicina medieval: un acercamiento sistemático a los problemas de los síntomas, curso, causas, transmisión, prevención y curación, en los que se observa la combinación de una especulación intensa basada sobre causas que ya no se aceptan en el s. XX con ideas muy acertadas en las que se basaban medidas prácticas $\mathrm{y}$ eficaces.

Las ideas más novedosas propuestas por los médicos de la Peste Negra concernían a los métodos de transmisión de la epidemia por contagio. Los griegos parecen haber tenido poco conocimiento de esto, atribuyendo todas las epidemias a una sola causa general, las miasmas. En la Edad Media, la idea de que enfermedades específicas podían ser contraídas por infección o por contagio fue elaborada al principio para la lepra y hacia el final del s. XIII fue aplicada a otras enfermedades como la erisipela, viruela, influenza, difteria y la fiebre tifoidea. Una enfermedad, el baile de San Vito, que se extendió por los paises germánicos al final del s. XIV y XV, también fue reconocida como contagiosa. La segregación de los leprosos se basaba sobre el aislamiento ritual descrito en la Biblia y se practicó en el mundo cristiano por lo menos desde el s. V. La lepra era todavía una seria amenaza en el s. XII, cuando parece que aumentó algo y se cuenta que por entonces en Francia una persona de cada 200 era leprosa, pero desde finales del s. XIII comenzó a declinar. Los médicos aprendieron a reconocer los síntomas con mayor precisión; a mediados del s. XIII Gilberto Anglico describió la anestesia local de la piel, que es uno de los mejores síntomas diagnósticos; y un siglo más tarde, Guy de Chauliac llamó la atención sobre el estado excesivamente graso de la piel. Tanto éxito tuvieron los medios de diagnóstico y el aislamiento precoz que hacia el s. XVI Europa estaba casi enteramente libre de lepra y medidas 


\section{Yolanda Guerrero Navarrete}

preventivas semejantes fueron adoptadas contra otras enfermedades infecciosas.

La primera comisión de higiene pública fue organizada en 1343 en Venecia, y en 1348 en Lucca, Florencia, Perussa, Pistoya y otras ciudades se dieron leyes para impedir que personas y mercancías infectadas entrasen en ellas. En 1377, Ragusa promulgó una nueva ley que ordenaba el aislamiento durante treinta días (llamada treintena) de todos los viajeros procedentes de regiones infectadas; y Marsella, en 1383, alargó este período a cuarenta días para los barcos que entraban a puerto, instituyendo así la cuarentena. Venecia abrió un hospital de cuarentena y publicó reglamentos sobre la aireación de las casas contaminadas, el lavado y soleado de las camas, el control de los animales domésticos y otros temas higiénicos. La higiene militar atrajo la atención desde las primeras cruzadas, cuando las pérdidas de hombres fueron muy considerables debido a la ignorancia de la higiene elemental; y en el s. XIII se escribieron varias obras sobre las precauciones que debían adoptarse por los soldados y los grandes grupos de peregrinos.

Una rama importante de la medicina donde se hicieron progresos notables en la Edad Media fue la oftalmología. Operaciones como la de cataratas fueron conocidas desde los tiempos clásicos y los árabes adquirieron gran destreza para tratar las afecciones oculares, utilizando ungüentos de cinc y realizando difíciles operaciones, como la remoción de un cristalino opaco. En Occidente el progreso más llamativo fue el invento de las gafas. La debilidad de la vista y especialmente la dificultad de leer con luz vespertina, era una grave calamidad; sin embargo, aunque las lentes se conocían desde hacía varios siglos en la Cristiandad y el Islam, es solamente al final del s. XIII cuando hay pruebas de que se usaban gafas con lentes convexas para compensar la presbicia. Roger Bacon lo propuso en 1266-1267. El invento de las gafas de entonces está asociado tradicionalmente con los nombres de ciertos frailes dominicos del norte de Italia, pero es más probable que las primeras gafas las hiciera, poco después de 1286 un inventor desconocido y que el invento fuera divulgado por un fraile que vió como las hacían y construyó entonces las suyas. Estas gafas antiguas eran, según parece, de lentes convexas; es solamente en el s. XVI cuando se sabe que se usaron lentes cóncavas para la miopía. De la cristiandad las gafas se extendieron a los árabes y a China.

En cirugía, los progresos comenzaron en Occidente con Rogerio de Salerno (fines s. XII). Parece que estuvo más influenciado por los médicos bizantinos que por los árabes. Muestra una aguda observación y una sólida experiencia clínica. Rompió y volvió a juntar huesos 
mal consolidados, trató las hemorragias con astringentes y con ligaduras, tenía un método eficiente de vendaje y describió una técnica interesante para la operación de hernia. Su sucesor, Rolando de Parma (s. XIII), mostró una destreza particular con las heridas de la cabeza y describió la trepanación y la elevación de las fracturas hundidas. También reconocío la necesidad de tener las manos limpias y de conservar caliente al enfermo. Estos cirujanos fueron en la mayor parte de su trabajo cirujanos de heridas y en su tratamiento siguiendo los consejos de Galeno provocaban la supuración utilizando pomadas grasas. Este tratamiento de las heridas fue rechazado en el s. XIII y XIV porque se afirmó que no sólo era innecesario sino perjudicial provocar la generación de pus y que la herida debía ser meramente limpiada con vino, unir los bordes de la herida con sutura y dejar luego a la naturaleza que la sanara. Sin embargo, a mediados del s. XIV se abandonó el tratamiento antiséptico de las heridas y se retornó a la supuración y a los ungüentos de Galeno.

Aunque la cirugía de la Edad Media se refería principalmente a las heridas y fracturas, se reconoció que el tratamiento quirúrgico era necesario para algunas otras dolencias y se adquirió una habilidad extraordinaria en algunas operaciones. La operación de la piedra y la cesárea se conocían desde tiempos clásicos y los árabes diseñaron instrumentos quirúrgicos especializados como bisturíes, agujas e hilo, sierras, jeringas auriculares, palancas y fórceps de todos los tipos. A mediados del s. XIII, Gilberto Anglico, canciller de Montpellier reconoció la importancia del tartamiento quirúrgico del cáncer y al final del s. XIII, el cirujano italiano, Guillermo de Saliceto describió el tratamiento de los niños hidrocéfalos extrayendo el líquido por un pequeño orificio hecho en la cabeza con cauterio. En la Italia del s. XV, los Branca emplearon la cirugía plástica para restaurar narices, labios y orejas; la técnica para ello fue sugerida por el médico romano Crelso. Para la nariz, la piel se retomaba en brida de la parte superior del brazo, un extremo se dejaba unido al brazo hasta que el injerto de la nariz había quedado firmemente unido.

La odontología fue una rama especial de la cirugía en la que se hicieron progresos en la Edad Media. Los médicos bizantinos y árabes describieron las caries, trataron y rellenaron los dientes enfermos e hicieron extracciones. En el s. XIV se recomendaba un polvo hecho de huesos de sepia y otras sustancias para limpiar los dientes y se describió la sustitución de los dientes perdidos por piezas de hueso de buey o por dientes humanos atados a los dientes sanos con alambre de oro. Los escritores de odontología más tardíos describieron la remoción 


\section{Yolanda Guerrero Navarrete}

de las partes enfermas por medio de una barrena o una lima y el relleno de la cavidad con hoja de oro.

Pese a todo, la prohibición eclesiástica de derramar sangre, y, por tanto, practicar la cirugía, hizo que esta disciplina nunca fuera considerada universitaria como la medicina y quedara por tanto relegada a una actividad artesanal de barberos itinerantes. Solamente en algunos sitios se practicaban autopsias post mortem para determinar las causas de la muerte. Los progresos de la cirugía, e incluso de la medicina, debían ser en este campo paralelos a los conocimientos, de anatomía que estudiamos más arriba.

Por último, los trastornos mentales eran atribuidos a tres tipos de causas: físicas, como la rabia y el alcoholismo; mentales, como la melancolía y la afasia; y espirituales, como la posesión diabólica. El tratamiento también se dividía en las mismas tres clases; y en cada caso, el método para curar al enfermo incluía en su forma más perfecta algún intento de sacar la causa de sus sufrimientos a la luz de su conciencia racional.

Muy relacionados con la medicina están los conocimientos de $\mathrm{Bo}$ tánica y Farmacología. En el siglo XIII, la literatura farmacéutica más específica está representada por dos series de textos de carácter, en principio distinto, aunque aparecen en manuscritos de sentido mixto. En principio, el Herbarius es un texto bastante sencillo, a menudo ilustrado, que describe medicamentos de origen vegetal con una sumaria descripción de la planta, con indicación de las partes que se utilizan, descripción de sus virtudes, forma sencilla de preparación e indicación de su uso. Suelen ser textos cortos que mencionan entre cuarenta y ciento cincuenta simples. Los herbarios cumplieron un lugar destacado en la Edad Media. La materia médica de Dioscórides fue el texto en que se basaron mayoritariamente. Los Lapidarios son lo mismo sólo que referidos a las drogas de origen mineral. Herbarios y Lapidarios aparecen asociados en numerosos manuscritos. El lapidario más famoso es el de Alfonso X con 130 rocas, gemas y minerales.

En materia de tecnología, la cristiandad occidental se vió influenciada completamente por las obras técnicas clásicas hasta el siglo XVII. Sin embargo, es una característica exclusiva de la cristiandad medieval el que se aplicara a uso industrial artificios técnicos que habían sido conocidos por la sociedad clásica, pero que ésta apenas había utilizado o los había considerado como juguetes. El resultado fue que, ya en el 1300 , la cristiandad occidental estaba utilizando muchas técnicas o desconocidas o no desarrolladas en el Imperio romano. Hacia el año 1500 , los paises más avanzados de Occidente, eran, en muchos aspectos 
de la técnica, superiores significativamente a cualquier sociedad anterior.

En tecnología agraria, las principales innovaciones medievales fueron: el arado pesado (siglo $\mathrm{X}$ ); avances muy notables en el aprovechamiento de la energía animal (a partir del s. XI); uso cada vez más frecuente del molino de agua; y, por último, la gran novedad fue la utilización masiva de los molinos de viento. Traídos por los cruzados de oriente, para poder ser utilizados en Europa occidental era indispensable introducir en ellos una importante modificación que permitiera orientarlos con arreglo a la dirección del viento. Aquí los vientos soplan en direcciones diversas, y si se quiere captar el viento suficiente para accionar el molino, éste o por lo menos la parte superior del mismo ha de poder girar sobre su eje vertical. El molino más antiguo giraba en su totalidad. Más tarde se ideó el molino del que sólo gira la estructura superior (s. XIV). Esta innovación hizo posible la construcción de unidades mucho mayores y más potentes. Había que orientar manualmente las aspas hacia el viento, pero esta tarea resultó más fácil más adelante con la introducción de manivelas y palancas.

En el campo de la tecnología artesanal la gran expansión del uso de molinos de agua y viento que tuvo lugar durante la última parte de la Edad Media, junto con el crecimiento de la industria, produjo una etapa esencialmente nueva en la técnica mecánica. La manivela se había conocido en su forma sencilla en la Antigüedad tardía. La búsqueda de un sistema que permitiese el movimiento rotatorio continuo y autogenerado y su transformación en movimiento lineal condujo a la invención del sistema biela-manivela en el s. XIV, invento del todo medieval.

Otro ámbito de desarrollo tecnológico importante fue la tecnología hidráulica (sobre todo en España por efectos de la dominación islámica). Algunas de las técnicas hidráulicas eran conocidas de la antigüedad clásica y preclásica, pero lo que distingue su uso en la Edad Media sobre todo en el ámbito hispánico, es la intensidad de su uso. Frecuentemente se dividen las técnicas de riego en dos grupos: las que transportan agua por gravedad (presas y qanats) y los artificios para elevar agua (cigoñal, pozos profundos, norias).

Una industria que se mecanizó rápidamente a fines de la Edad Media fue la producción de libros. De los diferentes elementos que entraban en la impresión, la fabricación de papel de lino parece haber comenzado en China en el s. I d.C., desde donde se extendió hacia Occidente a través de los países dominados por el Islam, para entrar en la cristiandad por España y el sur de Francia en el s. XII. El 


\section{Yolanda Guerrero Navarrete}

papel de lino era un materiai más apropiado para la impresión que los antiguos pergaminos costosos y el frágil papiro. Las tintas a base de aceite utilizadas en la impresión fueron elaboradas primero por los pintores más que por los calígrafos. Las prensas eran conocidas ya en la fabricación de vino y en el estampado gracias a la destreza adquirida pro los grabadores de madera y por los orfebres, que habían desarrollado una técnica para fundir metal. Las letras se desarrollaron en tres etapas principales, primero en China y luego en Europa, aunque, ya que las técnicas utilizadas en estos dos continentes eran muy distintas, es difícil decir hasta qué punto una influyó en la otra. En China apareció en el s. VI de nuestra era la impresión con bloques de madera, grabándose separadamente una plancha para cada página; en el s. XI, la impresión con caracteres móviles de madera; y en el s. XIV (Corea), con caracteres metálicos móviles. En Europa apareció el empleo de madera grabada para hacer las complicadas letras iniciales de los manuscritos por vez primera en un monasterio en Engelberg en 1147; la impresión con planchas apareció en Rávena en 1289 y era común en toda Europa hacia el s. XV; los caracteres móviles de metal se introdujeron al final del s. XIV, aparecieron en Limoges en 1381, en Amberes en 1417 y en Aviñón en 1444. La ventaja de los caracteres de metal fundido consistía en que cientos de copias de cada letra podían ser sacados de un solo molde, en vez de tener que grabarlas por separado, como ocurría con los caracteres de madera. Aunque la primera relación de su empleo es de los Paises Bajos, fue en Maguncia donde llegó a la perfección el empleo de un conjunto de caracteres moviles adecuadamente compuestos. En Maguncia, entre 1447 y 1455, Gutenberg y sus socios reemplazaron el antiguo método de fundir los caracteres en moldes de arena, primero por moldes adaptables de metal para hacer caracteres de plomo, luego perfeccionaron las matrices y prepararon caracteres de cobre. Estos fueron los inventos decisivos de la imprenta y con ellos se hizo posible la multiplicación de los libros en gran escala.

En el campo de la metalurgia e industrias de precisión los progresos también fueron tardíos. Hasta el final del s. XVIII, el material más improtante para la maquinaria y la construcción fue habitualmente la madera. Las primeras máquinas hechas enteramente de metal fueron las armas de fuego y los relojes mecánicos y éstos, en particular, son el prototipo de la moderna maquinaria automática en la que todas las piezas están cuidadosamente diseñadas para producir un resultado rigurosamente controlado. En el reloj mecánico, el uso de los engranajes, el principal punto de interés en la maquinaria antigua, se dominó 
Los contenidos de la ciencia y los progresos...

perfectamente. La Edad Media había heredado y descrito muchos artificios para medir el tiempo. Todos ellos son una parte tan esencial de los antecesores del reloj mecánico, pero en ninugno de estos artificios había engranajes. Los rasgos esenciales del reloj mecánico eran el empuje de un peso que ponía en movimiento un juego de ruedas dentadas y un mecanismo oscilante de escape que impedía la aceleración de la caída del peso, deteniéndolo a intervalos frecuentes. La primera ilustración de dicho mecanismo de escape aparece en un dibujo del arquitecto Villard de Honnecourt (s. XIII) para hacer girar lentamente un angel de manera que su dedo siempre señalara al sol. Es posible que los primeros relojes mecánicos se construyeran poco después. Probablemente, los primeros relojes auténticos cuyo mecanismo se conoce con precisión sean los del castillo de Dover, fechado habitualmente en 1348, pero que probablemente es más tardío y el reloj de Enrique de Vick colocado en Paris en el palacio real, hoy palacio de justicia, en 1370. La perfección de la maquinaria de estos relojes marca un límite en el diseño de los mismos, de modo que no se hizo ningún progreso real al respecto de la precisión hasta la aplicación del péndulo a los relojes en el s. XVIII, aunque antes de esta fecha se refinó su construcción. Efectivamnete los relojes antiguos eran muy grandes y las piezas las hacían los herreros. El reloj de De Vick estaba movido por un peso de 500 libras que caía 32 pies en veinticuatro horas y pesaba en total tres cuartos de tonelada. En el s. XV los relojes se hicieron más pequeños y eran utilizados en las casas, se usaron tornillos para juntar las piezas y el fin de siglo vió los primeros relojes de carrillón movidos por un resorte. Poseían una exactitud razonable si se los regulaba por la noche tras observar una estrella, y hacia 1500 la mayor parte de las ciudades tenía relojes públicos instalados en los muros exteriores de los monasterios, o de las catedrales, o en torrres especiales. Simplemente tocaban las horas o las señalaban en una superficie circular con 12 o 24 divisiones.

En el campo de la metalurgia, la fundición de campanas y cañones son quizá los procesos metalúrgicos más importantes, sobre todo porque se les exigía un acabado perfecto. Se comenzó a fabricar grandes campanas en el s. XIII, y en el XIV eran ya muy numerosas. El problema principal era fabricar campanas que sonaran con el tono apropiado. La nota de una campana varía según las proporciones y la cantidad de metal empleado, $\mathrm{y}$, aunque se podía hacer una afinación ulterior puliendo el borde si la nota era demasiado baja y puliendo la superficie interior de la cúpula sonora si la nota era muy aguda, era preciso que el fundidor fuera capaz de calcular el tamaño y las proporciones 


\section{Yolanda Guerrero Navarrete}

exactas para que diera una aproximación a la nota adecuada antes de que comenzara a fundir la campana.

La misma precisión se exigía para las armas de fuego. Las primeras armas de fuego aparecieron en Occidente relativamente temprano. Sin embargo, las verdaderas datan de la primera mitad del s. XIV, aunque parece que se fabricaban en China alrededor de un siglo antes. En ambas regiones se habían realizado previamente progresos notables en otros tipos de armas para arrojar proyectiles. En Occidente, hacia el final del s. XII, la catapulta accionada por contrapeso había comenzado a desplazar a los tipos antiguos de máquinas de artillería de torsión y tensión, que provenían de los romanos y escandinavos; a principios del s. XIV, la ballesta (fines del s. XI) se había convertido en un arma eficaz, con punto de mira y un mecanismo de gatillo; y el arco no era menos potente y preciso. El uso de la pólvora como propulsora de un cañón eficaz fue simplemente el último de una serie de progresos (trabuco con proyectiles de piedra calibrados, sitio de Lisboa por cruzados en 1147); y las armas de fuego no reemplazaron inmediatamente a las otras armas de arrojar proyectiles, aunque se habían convertido en la principal arma de la artillería al final del s. XIV. Puede ser que el cañón haya sido utilizado en Occidente ya en el sitio de Berwick en 1319 y por los ingleses en Crécy en 1346. Se sabe con certeza que los cañones fueron usados por los ingleses para capturar Calais en 1347 y, según Froissart, los ingleses usaron 400 cañones, probablemente morteros, para sitiar St. Malo en 1378.

De los componentes de la pólvora, el salitre parece que era conocido en China antes del s. I a.C. y parece que el conocimiento de las propiedades explosivas de una mezcla en proporción adecuada de salitre, azufre y carbón vegetal fue conseguido alrededor del año 1000 . En Occidente se había utilizado mucho antes en la guerra otras mezclas inflamables. Los bizantinos utilizaron una forma perfeccionada, el "fuego griego", probablemente una mezcla de cal viva, nafta, y alquitrán de petróleo y azufre, contra la flota musulmana en el sitio de Constantinopla en el 673 y más tarde. La misma pólvora fue conocida en Occidente en la segunda mitad del s. XIII, quizá introducida desde China por los mongoles. Roger Bacon menciona en dos de sus obras un polvo explosivo, y señala que su potencia podía ser aumentada encerrándolo en un instrumento hecho de material resistente. La más antigua receta conocida en Occidente para hacer pólvora se conserva en un manuscrito latino de alrededor de 1300 , el Liber ignium, atribuido a un cierto Marcos el Griego, de quien no se conoce nada. 
Los contenidos de la ciencia y los progresos...

Occidente, habiendo descubierto las propiedades explosivas y propulsoras de la pólvora, sobrepasó rápidamente a China en la fabricación de armas. Los primeros cañones occidentales fueron fabricados con metal similar al usado para las campanas, a menudo lo eran por el mismo fundidor y los principales centros de fabricación fueron Flandes, Alemania y en menor grado Inglaterra (el primero conocido data de 1327). A mediados del s. XIV, los cañones eran fundidos de metal cuproso y a finales de siglo eran también fabricados con barras de hierro forjado mantenidas juntas por bandas de hierro. En el s. $\mathrm{XV}$, los cañones adquirieron un tamaño considerable, en particular los de hierro forjado. Estos cañones antiguos se cargaban todos por la boca, disparando al principio grandes piedras redondas y luego balas de metal fundido. Los proyectiles de plomo se usaron desde el s. XIV con armas más pequeñas. Muy pronto se intentó la carga por la culata, pero no era posible dar a las superficies metálicas un acabado lo suficientemente preciso para conseguir un cerrojo completamente estanco a los gases. Se introdujo una forma primitiva de rayado en los cañones de bronce, y durante el siglo XV se comenzó a establecer una normalización de los cañones y de los proyectiles. A principios del s. XVI se realizó un gran avance en la fabricación de cañones gracias a la introdución de un método de barrenado de los cañones fundidos de bronce o hierro, de manera que podía dárseles un acabado preciso. Con la aparición de cañones barrenados con precisión comenzó un período nuevo en la historia de la artillería que duró hasta el s. XIX.

La elaboración del vidrio era muy conocida en el Mundo Antiguo, y en varias partes del Imperio romano se hacían vajillas excelentes, cuencos, copas, botellas y otros objetos domésticos a partir del vidrio soplado, desarrollándose, asimismo, el arte de grabar el cristal. A principios de la Edad Media se ejercía una técnica muy refinada en la elaboración del vidrio en Bizancio, en varios centros árabes y también, aunque muy oscuramente, en Occidente. No fue hasta el s. XIII cuando la elaboración del vidrio comenzó a renacer en Occidente. El centro más famoso fue Venecia. Aunque desde este siglo se hicieron progresos en España, Francia e Inglaterra, no fue hasta el XIV cuando empezó a fabricarse generalizadamente fuera de Italia. La mayor parte del vidrio medieval era soplado. Para hacer vidiro plano la arena debía estar exenta de óxido de hierro y se requerían el carbonato de cal, el sulfato de sodio y algún tipo de carbón. El método de hacer vidrio plano consistía en soplar una gran burbuja que se trabajaba para hacer un cilindro grande, hueco, que se colgaba desde la plataforma 


\section{Yolanda Guerrero Navarrete}

sobre la que estaba el vidriero, y que era luego cortado y aplanado. Este método limitaba el tamaño de la lámina.

El principal uso del vidrio en la Edad Media fue para ventanas y vajilla doméstica. Las ventanas de vidrieras para las iglesias aparecieron ya en el s. XII y el cristal pintado en el XIV. Las vasijas de vidrio para usos comunes se hicieron frecuentes antes del XVI; el estaño y la cerámica barnizada eran los utensilios habituales de la vajilla; pero desde el s. XIV, el cristal fue usado con más frecuencia. $\mathrm{Ya}$ en el siglo XIII hay referencias al vidrio usado para hacer utensilios científicos y ya en el s. XV los aparatos para destilar eran hechos de vidrio. El desarrollo de la Química se hubiera retrasado mucho sin la aparición del uso del cristal que permanece neutro en el experimento, que es transparente y resiste temperaturas relativamente altas y es relativamnete fácil de limpiar y sellar. Algo parecido debe la óptica al cristal. Los árabes habían fabricado lentes ya en el s. $\mathrm{XI}$ y las lentes fueron estudiadas por los grandes autores latinos de óptica del s. XIII. Aunque el cristal óptico medieval no poseía la perfección del que se elaboró a partir del s. XVIII, era lo suficientemente bueno para hacer posible el invento de las gafas al final del s. XIII.

En otras industrias químicas, tanto en la metalurgia como en la elaboración de vidrio, los artesanos medievales adquirieron un considerable saber empírico. En la cerámica se manifestó una considerable maestría de los procesos implicados, lo mismo que en la fabricación de tejas y ladrillos, en el curtido y en la fabricación de jabones, en el proceso de malteado, de la adición de la levadura y de fermentación implicados en la fabricación de cerveza, vino y en la destilación de licores. También se mostró una considerable habilidad en el tinte de lana, seda y lino con tintes vegetales (glasto, rubia, gualda, líquenes) y en la fijación del tinte con mordientes, de los que los más habituales eran el alumbre, la potasa de las cenizas de la madera, el sulfato de hierro y otros. Los tratados sobre la fabricación de pigmentos, colas, secantes y barnices descritos desde los s. VIII al XVI continenen una gran variedad de recetas que dan indicaciones prácticas de cómo preparar ciertas sustancias químicas. Al principio del s. XII se hace mención de las pinturas al óleo, aunque las propiedades secantes de éstas no fueron perfeccionadas antes de los Van Eyck (comienzos del s. XV), de manera que se secaran lo suficientemente rápido para poder dar varios colores a la vez. Los pintores e ilustradores medievales aprendieron cómo preparar una gran variedad de colores de origen vegetal y mineral. La tinta negra utilizada ordinariamente en los manuscritos 
medievales era negro de humo mezclado con cola. La habilidad práctica adquirida por estas industrias ayudó a poner las bases de la química moderna.

En el campo de los transportes alrededor del s. XIV se introdujo una mejora en la navegación fluvial por medio del empleo de esclusas en los canales. Se dotó de nuevas posibilidades al transporte terrestre al hacer carreteras de adoquines asentadas sobre un lecho de tierra suelta o arena y mediante mejoras en los vehículos de ruedas, inlcuida (en el s. XIII), la invención de la carretilla. También se intentó la mecanización de los vehículos terrestres ya en 1420, cuando Fontana describió el velocípedo. Al final del s. XVI parece que se construyeron carros impulsados por maquinaria movida por el hombre y por velas en los Paises Bajos. El cielo había atraído la atención en Occidente por lo menos desde el s. XI, cuando Oliver de Malmesbury, según se dice, se rompió las piernas en un intento de planear sobre una torre con alas adaptadas a sus pies y manos. También Roger Bacon estuvo interesado por el vuelo. Leonardo da Vinci diseñó una máquina voladora que movía las alas como un pájaro.

El mar fue el medio en el que se formaron las fortunas de los mercaderes. Algunos avances propiamente medievales fueron: un nuevo procedimiento de construcción la obra viva y el armazón de los barcos (mediterráneo, s. X) antes que la carcasa, al revés que en época clásica (más barato); el uso de la vela latina o triangular (s. VIII mediterráneo oriental); la brújula (1250 -1350); el timón de codaste (1242), que sustituyó al remo lateral; el astrolabio (fines del s. XII aunque de utilización más tardía); y nuevos tipos de barcos, más adaptados a las necesidades y características de la navegación y comercio marítimo del momento.

Un progreso importante relacionado con estas mejoras de los métodos de transporte fue la aparición de los primeros buenos mapas en Occidente desde el tiempo de los romanos. Los primeros mapas medievales auténticos fueron los portulanos o cartas marinas para los navegantes. El portulano más antiguo conocido es la Carte Pisane de finales del s. XIII, pero la relativa perfección de su técnica sugiere que se habían hecho otras antes que han desparecido. Se dice que los marineros genoveses mostraron a San Luis rey de Francia su posición sobre un mapa cuando navegaba hacia Túnez en 1270. Algunas de las pruebas sugieren el origen escandinavo de los portulanos, pero se sabe que los árabes poseían cartas marinas desde una fecha remota y que también fueron desarrolladas por los bizantinos, catalanes y genoveses. El uso de la legua catalana para las distancias en todos los portulanos conocidos 


\section{Yolanda Guerrero Navarrete}

quizá apoye la pretensión catalana de la prioridad de dicho origen, pero esa costumbre podía haberse establecido más tarde por razones de comodidad. De hecho, el problema del origen de los portulanos está sin decidir. El rasgo nuevo de los portulanos, comparados con los mappae mundi simbólicos tradicionales de la antigüedad, reside en que eran hechos para ser usados como guías para una zona determinada. Estaban hechos por hombres avezados y se basaban en la determinación directa de las distancias y azimuts mediante la corredera y la brújula. Generalmente, se limitaban a la línea de costa y no contenían indicaciones de la latitud y de la longitud. Estaban cubiertos por una red de líneas de rumbos que daban la orientación, según la brújula, de los lugares sobre el mapa. Las líneas de rumbo irradiaban desde varios puntos dispuestos en círculo que correspondían a los puntos señalados sobre la rosa de los vientos.

Tanto de regiones interiores como de las costas se hicieron mapas exactos por hombres instruidos a partir del s. XIII, cuando científicos como Roger Bacon mostraron un interés por la geografía real. El mismo Bacon no hizo ninguna contribución práctica a la cartografia aunque se dice que su creencia en que la anchura del océano entre Europa y China no era muy grande influyó en Colón. Ya en 1250 Mateo Paris dibujó cuatro mapas reconocibles de Gran Bretaña conteniendo detalles como el de la muralla romana, los caminos y las ciudades. Entre 1325 y 1330, un cartógrafo desconocido hizo un mapa notablemente desarrollado y exacto de Inglaterra que muestra los caminos y las distancias probablemente estimadas por los viajeros. Alrededor de la msima época se hicieron buenos mapas del norte de Italia y en1375 la llamada escuela mallorquina de cartógrafos realizó para Carlos V de Francia el famoso Mapamundi Catalán, que combinaba las ventajas de los portulanos y de los mapas terrestres y que incluía Africa del Norte y partes de Asia. Este centro mallorquín había reunido una gran cantidad de información comercial y marinera y fue el precursor del instituto colonial y naval fundado por el príncipe Enrique el navegante en Sagres en 1437.

Estos mapas primitivos no contenían indicaciones de la latitud ni de la longitud, aunque la latitud de muchas ciudades había sido determinada con el astrolabio. Después de la traducción a comienzos del XV de la Geographia de Ptolomeo los cartógrafos empezaron a adoptar el método de longitudes y latitudes empleado por este autor. Esta obra transformó gradualmente la cartografia al acentuar la necesidad de una medida lineal exacta del arco del meridiano, requisito esencial de la cartografia terrestre exacta. 


\section{Notas}

1 Por ello muy pocas notas aclaratorias salpicarán este texto. Los contenidos del mismo harán en todo momento referencia a la bibliografia que completa el presente artículo

2 Las obras generales sobre ciencia y técnica en la Edad Media citadas en bibliografia servirán para introducirnos en la etapa medieval de estas culturas y sus aportaciones y logros científicos.

3 En cierto modo ello tambiés es debido a un planteamiento unilateral de la historia de la ciencia. Hasta la fecha es muy dificil encontrar historiadores dispuestos a cultivar este nivel de expresión de un sistema social dado. La inmensa mayoría de las historias de la ciencia que poseemos, para todos los períodos históricos, han sido confeccionadas desde los departamentos de filosofia de la historia o de historia de la ciencia de las facultades de filosofia y ciencias respectivamente. Ello proporciona a los resultados una perspectiva nada desdeñable pero, sin duda, insuficiente para el historiador. Sólo en la medida en que nos acerquemos «históricamente» al problema del conocimiento científico como un aspecto más de un sistema social dado, estaremos dimensionando en su estricta realidad la evolución y verdaderas dimensiones de la ciencia en cada período histórico estudiado.

4 Este apartado debe mucho a la obra de Gurievitch mencionada en la bibliografia.

5 A efectos de la elaboración de este apartado, he seguido una clasificación que no se corresponde ni con la clasificación actual de las ciencias, ni con ninguna de las vigentes en la Edad Media. Sino que he tratado de realizar una aproximación adecuada a ambas que, por otro lado, es la que siguen la mayoría de las obras dedicadas a la ciencia y técnica medievales.

\section{Bibliografía}

Crombie, A C. (1987): Historia de la Ciencia: De San Agustín a Galileo. 2 vols. Madrid. ESTEVA DE SAGRERA, J. (1991): La química sagrada: de la alquimia a la química del siglo XVII. Madrid.

GLICK, T. F. (1992): Tecnología, ciencia y cultura en la españa medieval. Madrid.

Grant, E. (1983): La física en la edad Media. México.

GURIEVICH, A. (1990): Las categorias de la cultura medieval. Madrid.

Mason, S. F. (1994): Historia de las ciencias. 1. La ciencia Antigua, la ciencia en Oriente y en la Europa medieval. Madrid.

VERNET, J.(1979): Historia de la ciencia española. Madrid.

- (1979): Estudios sobre historia de la ciencia medieval. Barcelona.

TATON, R. (ed.) (1971): Historia general de las ciencia. I: La ciencia antigua y medieval. Barcelona.

VV.AA.(1988): Estudios sobre historia de la ciencia y de la técnica. Actas del IV Congreso de la Sociedad Española de Historia de las ciencias y de las Técnicas. Vol. II. Valladolid. 